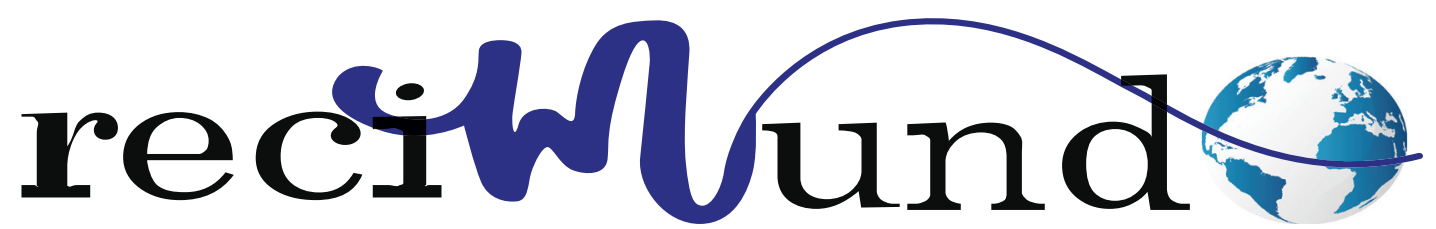

Revista Científica Mundo de la Investigación y el Conocimiento

DOI: 10.26820/recimundo/4.(4).octubre.2020.144-151

URL: http://recimundo.com/index.php/es/article/view/898

EDITORIAL: Saberes del Conocimiento

REVISTA: RECIMUNDO

ISSN: 2588-073X

TIPO DE INVESTIGACIÓN: Artículo de Revisión

CÓdIGO UNESCO: 3202 Epidemiología

PAGINAS: $144-151$

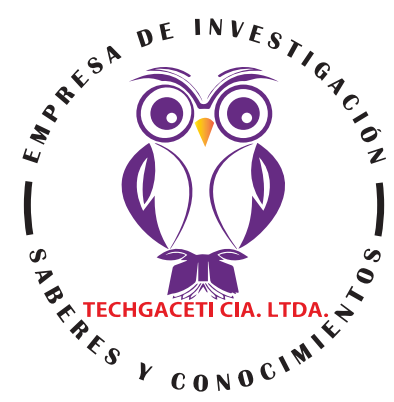

\title{
Lidiar con el estrés durante el brote de Covid-19
}

Dealing with stress during the Covid-19 outbreak

Lidando com 0 estresse durante 0 surto de Covid-19

Jessenia Paola Ochoa Bustamante'; Silvio Eleuterio Ortiz Dueñas²; Janeth Mabel Rojas Riera ${ }^{3}$

RECIBIDO: 10/07/2020 ACEPTADO: 26/08/2020 PUBLICADO: 30/10/2020

1. Master Universitario en Prevención de Riesgos Laborales, Obstetra; Médico; Investigadora Independiente; Guayaquil, Ecuador; pao_ochoab@hotmail.com; iD https://orcid.org/0000-0003-2069-0371

2. Especialista en Ginecología y Obstetricia; Médico; Centro de salud Bastión Popular Tipo C; Guayaquil, Ecuador; seod801@ hotmail.com; (D) https://orcid.org/0000-0001-8080-2748

3. Especialista en Medicina Familiar y Comunitaria, Médico; Investigador Independiente; Guayaquil, Ecuador; mabelina87@ gmail.com; (iD https://orcid.org/0000-0002-1612-760X

CORRESPONDENCIA

Jessenia Paola Ochoa Bustamante

pao_ochoab@hotmail.com

Guayaquil, Ecuador 


\section{RESUMEN}

El ser humano está acostumbrado a tener el control sobre las situaciones cotidianas de su vida, la pandemia por el Covid-19, decretada en Marzo por la Organización Mundial de la Salud, lo que obligó al confinamiento voluntario y obligatorio en todos los países del mundo. Acabo con esa cotidianidad, trasladándola a los hogares. El miedo por el contagio más el confinamiento ha traído como consecuencia niveles de estrés en muchas personas, lo que ha generado ansiedad, depresión y otras consecuencias sobre la salud mental. La metodología de la investigación, es una revisión bibliográfica, que se apoyó en medios electrónicos para la obtención primaria de la información. Las conclusiones más destacadas, es que el mal manejo de la información por redes sociales, televisión, entre otros ha generado niveles de estrés y ansiedad, en muchos casos por informaciones tergiversadas y negativas. Las recomendaciones para afrontar el estrés van orientadas a la búsqueda de ayuda terapéutica, la disminución de contenido mal sano que este en internet y en medios audiovisuales sobre el Covid-19 y el empleo de pensamientos positivos y distracciones que ayuden a la salud mental.

Palabras clave: Salud, Mental, Estrés, Ansiedad, Redes.

\section{ABSTRACT}

Human beings are used to having control over the daily situations of their life, the Covid-19 pandemic, decreed in March by the World Health Organization, which forced voluntary and mandatory confinement in all countries of the world. I put an end to that daily life, transferring it to homes. The fear of contagion plus confinement has resulted in stress levels in many people, which has generated anxiety, depression and other consequences on mental health. The research methodology is a bibliographic review, which relied on electronic means to obtain the primary information. The most outstanding conclusions are that the mishandling of information through social networks, television, among others, has generated levels of stress and anxiety, in many cases due to distorted and negative information. The recommendations to cope with stress are aimed at seeking therapeutic help, reducing unhealthy content on the internet and in audiovisual media about Covid-19, and using positive thoughts and distractions that help mental health.

Keywords: Health, Mental, Stress, Anxiety, Networks.

\section{RESUMO}

O ser humano está acostumado a ter controle sobre o cotidiano de sua vida, a pandemia Covid-19, decretada em março pela Organização Mundial da Saúde, que obrigou ao confinamento voluntário e obrigatório em todos os países do mundo. Acabei com esse cotidiano, transferindo para os lares. O medo do contágio mais o confinamento resultou em níveis de estresse em muitas pessoas, o que gerou ansiedade, depressão e outras consequências na saúde mental. A metodologia da pesquisa é uma revisão bibliográfica, que contou com meios eletrônicos para obtenção das informações primárias. As conclusões mais marcantes são que o manuseio incorreto da informação por meio das redes sociais, televisão, entre outras, tem gerado níveis de estresse e ansiedade, em muitos casos devido a informações distorcidas e negativas. As recomendações para lidar com o estresse visam buscar ajuda terapêutica, reduzir conteúdos não saudáveis na internet e na mídia audiovisual sobre a Covid-19, e usar pensamentos positivos e distrações que ajudam a saúde mental.

Palavras-chave: Saúde, Mental, Estresse, Ansiedade, Redes. 


\section{Introducción}

Ribot Reyes, Chang Paredes, \& González Castillo (2020) citando a González Menéndez \& Sandoval Ferrer, 2019; Muñoz CO, Restrepo D \& Cardona D, 2016; comentan que:

"La Organización Mundial de la Salud (OMS) ha equiparado la salud mental con el bienestar subjetivo, la percepción de la propia eficacia, autonomía, competencia, dependencia intergeneracional y autorrealización de las capacidades intelectuales y emocionales. Incluye, por tanto, las capacidades para afrontar las tensiones normales de la vida, trabajar de forma productiva y fructífera y para hacer contribuciones a la comunidad" (pág. 3).

En tal sentido Cedeño, Cuenca, Mojica, \& Portillo (2020) afirman que:

"La sociedad actual protagoniza una serie de vertiginosos cambios y crecientes transformaciones a nivel económico, político, social, cultural y ambiental, como producto d en la actualidad, la pandemia causada por la emergencia de una cepa viral denominada SARS-CoV-2. A pesar de todos los recursos empleados para contrarrestar la propagación del virus, y disminuir el impacto, incluyendo la salud mental, se necesitan estrategias globales adicionales para abordar los nuevos desafíos que esta pandemia ha originado" (pág. 64).

En este sentido Scholten, y otros (2020), agregan que:

"En el mundo moderno, uno de los principales insumos que utilizamos para construir la realidad es la información provista por los diversos canales de noticias, que nos permiten recibir las novedades y comprender lo que sucede en nuestra ciudad, en nuestro país, en el continente y en el mundo" (pág. 5).
Scholten, y otros (2020), citando a Eppler \& Mengis, continuan sus afirmaciones sobre este tema cuando indican que:

"En el transcurso del siglo XXI, se ha puesto en evidencia un fenómeno que los especialistas denominan sobrecarga informativa, infoxicación o infobesidad, especialmente apreciable a partir de la veloz expansión de la internet, las redes sociales (e.g., Facebook, Twitter), los dispositivos móviles (e.g., smartphones, tablets) y las aplicaciones de mensajería (e.g, WhatsApp, Telegram), que se han integrado en la vida cotidiana de miles de millones de personas" (pág. 5).

Scholten, y otros (2020) citando a Bawden \& Robinson, 2009; Pantic, 2014; Sevinc \& D'Ambra, 2010, afirman que:

"Frente este panorama, es preciso señalar las consecuencias psicológicas y los efectos sobre la salud mental de este fenómeno que, si bien no es nuevo, se han vuelto particularmente evidentes en el marco de esta pandemia. Las investigaciones que se realizan desde hace más una década, además de efectos a mediano y largo plazo, muestran que la sobrecarga de información incrementa los niveles de estrés y ansiedad, y puede tener efectos nocivos en la autoestima" (págs. 5,6).

Ruiz, Arcaño, \& Pérez (2020) citando a Infobae 2020; Inchausti et al., 2020; BBC, 2020 afirman que:

"Esta nueva enfermedad, ha ocasionado un impacto mundial sin precedentes, tanto por lo imprevisto y la rapidez de su propagación a nivel internacional, como por el elevado número de fallecidos. La población mundial está asustada, y con frecuencia se acerca a comportamientos paranoides. Las consecuencias socioeconómicas son casi impredecibles y no muy esperanzadoras global y regionalmente" (pág. 154).

El aislamiento, el distanciamiento físico, el 
cierre de escuelas y lugares de trabajo son desafíos que afectan, y es natural sentir estrés, ansiedad, miedo y soledad en estos momentos (Ruiz, Arcaño, \& Pérez, 2020).

\section{Metodología}

La metodología de la investigación, es una revisión bibliográfica apoyada en medios electrónicos en donde se ubicaron diferentes autores que abordan el tema de estudio, y lo que se busca es mostrar las diferentes técnicas o elementos de carácter psicológico para afrontar el estrés.

\section{Resultados}

Sobre este particular Cedeño, Cuenca, Mojica, \& Portillo (2020), afirman que:

"Los informes iniciales indican que los temores de las personas sobre el coronavirus se relacionan con diferentes temas. Particularmente, Taylor y col desarrollaron y validaron recientemente las escalas de estrés COVID (CSS) e identificaron cinco factores de estrés y síntomas de ansiedad relacionados con el coronavirus en dos muestras grandes en Canadá y los Estados Unidos: (1) miedo y peligro de contaminación, (2) miedo a las consecuencias económicas, (3) xenofobia, (4) verificación compulsiva y búsqueda de garantías y (5) síntomas de estrés traumático sobre COVID-19 (pág. 66).

\section{Y continúan diciendo que:}

"Paralelamente, pero en base a un análisis conceptual, otros autores identificaron cuatro dominios de miedo: (1) Temor por el cuerpo, (2) miedo por los demás, (3) miedo a no saber, y (4) miedo a la inacción. Si bien estos estudios proporcionan una visión general inicial de los diferentes temas relacionados con el miedo y los comportamientos conexos con la ansiedad por la pandemia de COVID-19, no dieron una indicación de la relativa prevalencia de estos diferentes temas de miedo por los que las personas se preocupan. Además, el miedo es una emoción subjetiva que puede implicar idiosincrasia. Por lo tanto, las preocupaciones que tienen los individuos pueden extenderse más allá de las identificadas en esa investigación" (pág. 66).

\section{Cómo actuar ante la nueva situación}

- Las personas necesitan tener la sensación de que viven en un ambiente seguro y controlado. La inseguridad y la incertidumbre vinculadas con la pandemia, aunado a la falta de claridad sobre el fenómeno en curso, facilita la aparición de conductas de ansiedad que pueden derivar en conductas egoístas y de búsqueda individual de soluciones para problemáticas que son colectivas. Por ello, es importante fomentar la solidaridad, entendiendo que los otros no son nuestros enemigos/as, sino que incluso pueden constituirse en nuestros únicos auxilios (Gallegos, y otros, 2020).

- Es importante ser prudente y no generar alarma innecesaria: ni magnificar el riesgo ni desestimar su peligro para evadir la sensación de miedo. El manejo adecuado de la información oficial, pertinente y sustentada en evidencia continua es crucial para desactivar falsas alarmas, así como para calmar ansiedades y propiciar conductas más adaptativas (Gallegos, y otros, 2020).

- Es importante tener en cuenta que no todas las personas reaccionarán de la misma forma frente a las eventuales situaciones de crisis que se presenten; algunos/ as expondrán comportamientos no habituales, otros/as quizás sorprendan por lo inesperado de sus reacciones, habrá quienes tendrán mayor adaptabilidad a las nuevas circunstancias mientras que otros/as todo lo contrario. Es importante que aquellas personas que han presentado un mejor afrontamiento de las situaciones de crisis sirvan de referencia de consulta y ayuda y puedan transmitir un mensaje de objetividad, tranquilidad y

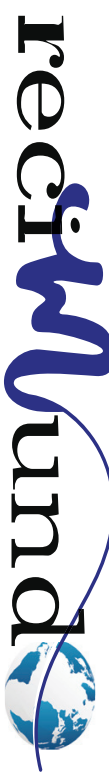


optimismo (Gallegos, y otros, 2020).

Tabla 1. Recomendaciones en salud mental durante la pandemia COVID-19

\begin{tabular}{|l|l|}
\hline \multicolumn{1}{|c|}{ Proporcionar información útil } & $\begin{array}{l}\text { Es importante que las personas } \\
\text { entiendan los datos correctamente para } \\
\text { reducir el exceso de estrés (p. ej., } \\
\text { ansiedad, depresión, etc.) provocadas } \\
\text { por una percepción inapropiada. }\end{array}$ \\
\hline $\begin{array}{l}\text { Trabajar con funcionarios de salud } \\
\text { pública para formular comunicaciones } \\
\text { apropiadas a la cultura de la población, } \\
\text { y así motivar como movilizar para una } \\
\text { preparación sin generar el pánico. }\end{array}$ & $\begin{array}{l}\text { Expandir conciencia y participación } \\
\text { pública del progreso continuo en las }\end{array}$ \\
$\begin{array}{l}\text { Ya que la indignación puede venir } \\
\text { principalmente por errores y deficiencias } \\
\text { en la prevención y el control de la } \\
\text { epidemia. }\end{array}$ \\
\hline $\begin{array}{l}\text { Trabajar con funcionarios de salud } \\
\text { pública y entidades de salud para } \\
\text { proporcionar apoyo a los pacientes en } \\
\text { cuarentena y/o aislamiento social. }\end{array}$ & $\begin{array}{l}\text { Asegurar el suministro de servicio de } \\
\text { tratamiento médico. Es fundamental } \\
\text { establecer un servicio médico para tratar } \\
\text { la enfermedad y dejar que las personas } \\
\text { sepan cómo acceder a él. Las personas } \\
\text { pueden obtener ayuda a tiempo si están } \\
\text { infectadas. Puede mejorar sentido de } \\
\text { control de las personas sobre los riesgos, } \\
\text { evitando así la percepción excesiva de } \\
\text { riesgo social. }\end{array}$ \\
\hline $\begin{array}{l}\text { Trabajar con funcionarios y entidades de } \\
\text { salud locales para garantizar apoyo } \\
\text { psicosocial y de otro tipo para el personal } \\
\text { de salud. }\end{array}$ & $\begin{array}{l}\text { Proporcionar más servicios de } \\
\text { entretenimiento en la puerta para } \\
\text { abordar la buena calidad de vida. Las } \\
\text { personas pueden estar más dispuestas a } \\
\text { cooperar cuando se cumplen sus } \\
\text { requisitos de vida y entretenimiento, } \\
\text { como en línea, } \\
\text { entretenimientos. }\end{array}$ \\
\hline
\end{tabular}

Fuente: (Ramírez-Ortiz, Castro-Quintero, Lerma-Córdoba, Yela-Ceballos, \& Escobar-Córdoba, 2020).

\section{Intervención psicoterapéutica}

En tal sentido Huarcaya-Victoria (2020), nos argumenta que:

"En China, la intervención psicoterapéutica en línea es durante las 24 horas, todos los días de la semana. En estos programas se incluyen intervenciones como la terapia cognitivo-conductual para tratar la depresión, ansiedad e insomnio. También se han desarrollado programas de inteligencia arti- ficial que pueden ser de utilidad. Por ejemplo, se pueden identificar las personas con riesgo de suicidio a través del programa Tree Hole Rescue" (pág. 332).

Y continúa Huarcaya-Victoria su afirmación exponiendo que:

"Otra posible intervención es la terapia de cartas estructuradas, la cual puede realizar la función de consulta, diagnóstico y tratamiento. Se envía un formulario con pregun- 
tas estructuradas en las que se incluye una página para el paciente y una página de intervención y continuación (pág. 332).

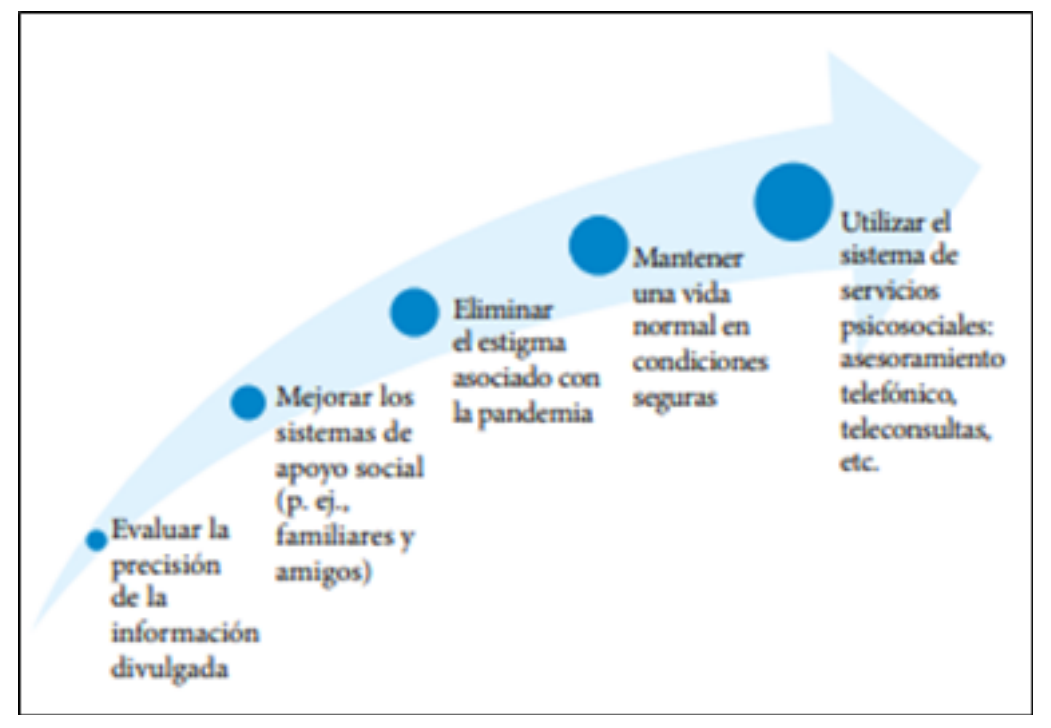

Imagen 1. Sugerencias de los expertos del Peking University Sixth Hospital para que la población afronte el estrés producido durante la pandemia de COVID-19

Fuente: (Huarcaya-Victoria, 2020)

Sobre este particular Huarcaya-Victoria (2020), comenta al respecto que:

"El gobierno chino realizó un esfuerzo para concientizar a la población sobre las estrategias de prevención e intervención, proporcionando actualizaciones diarias en las redes sociales y sitios webs. Esta información, actualizada y precisa, debe centrarse en el número de casos recuperados, el tratamiento (desarrollo de medicamentos o vacunas) y el modo de trasmisión, así como sobre el número de casos infectados y su ubicación. Si las personas reciben suficiente información y confían en el gobierno y en las autoridades de salud se podría reducir la ansiedad y la vulnerabilidad percibida" (pág. 333).

\section{Manejo del estrés}

En este sentido Flórez (2020) nos dice:

"Es conocido el efecto negativo del estrés crónico sobre nuestro sistema inmunológi- co, de tal manera que la tensión agregada por la situación actual puede elevar nuestros niveles de cortisol y disminuir la capacidad de nuestro organismo de luchar contra las infecciones" (pág. 176).

Continúa Flórez argumentando que:

"Si bien es cierto que no podemos "borrar" a la incertidumbre propia de tiempos como los que estamos viviendo, sí que podemos controlar nuestra respuesta al estrés. Además de una alimentación saludable, actividad física moderada y sueño suficiente hay otras medidas que pueden resultar de utilidad como la meditación y los ejercicios de respiración" (pág. 176).

\section{Otras ayudas}

Barrios-Borjas, Béjar-Ramos, \& Cauchos-Mora (2020), opinan es este sentido que:

"En la situación actual, la tecnología permite 
un mayor acceso al apoyo emocional, mediante uso de aplicaciones utilizadas desde el móvil, hasta cursos y asesoría en línea de acceso gratuito, con el fin de ayudar a comprender y controlar las emociones generadas a partir del confinamiento. Diversos países han incorporado servicios para la intervención de emergencias de crisis psicológicas: en Perú se han propuesto medidas de cuidado y primeros auxilios psicológicos para el personal de salud; en Chile y Brasil se ha convocado a expertos en el tema y se han generado recomendaciones, aplicaciones móviles y líneas de ayuda, dispuestas por grupos de riesgo, con el fin de mantener la humanidad del equipo de respuesta, brindar información clara y no generar pánico. Si bien las aplicaciones o las asesorías remotas no sustituyen por completo la atención personal, su uso ha demostrado beneficios en enfermedades crónicas, además de algunas ventajas: menor saturación de los establecimientos de salud, menor exposición al virus y reducción de costos en la atención" (pág. 364).

\section{Conclusiones}

Definitivamente la pandemia del Covid-19, ha trastocado los niveles mentales de los ciudadanos, en la mayoría de los casos, producidos por el temor al contagio y al confinamiento obligatorio, los rasgos más comunes sin duda alguna han sido depresión y ansiedad, y esto se puede generar en todos los niveles sociales y en todas las edades, sin mencionar a aquellas personas que más están en contacto con la pandemia como es el personal de salud. Sin embargo se ha detectado que el mal manejo de la información en redes sociales, televisión, radio, entre otros. También es un causal importante en los niveles de ansiedad, depresión, miedo y angustia que se han presentado en personas con estrés causados por la pandemia.

La bibliografía consultada en la mayoría de los casos coincide en buscar ayuda tera- péutica con un especialista para disminuir los niveles de estrés que se presenten, de igual manera las recomendaciones van tendientes a disminuir aquella información toxica, nociva y de fuente no confiable que tergiverse la verdad acerca del Covid-19.

La distracción dentro del entorno familiar y la búsqueda sana de utilizar la mente en acciones y pensamientos positivos, es un recurso también muy valioso para alejar el estrés y los problemas que la pandemia está causando.

\section{Bibliografía}

Barrios-Borjas, D. A., Béjar-Ramos, V., \& Cauchos-Mora, V. (2020). Salud mental en tiempos de COVID-19. La tecnología como herramienta de soporte. Gaceta Médica, 156, 364-365.

Cedeño, N. J., Cuenca, M., Mojica, Á., \& Portillo, M. (2020). Afrontamiento del COVID-19: estrés, miedo, ansiedad y depresión. Enfermería Investiga, 5(3), 63-70.

Flórez, L. G. (2020). Pandemia COVID-19:¿ Qué más puedo hacer? Rev. Fac. Med. Hum. Abril, 20(2), 175-177.

Gallegos, M., Zalaquett, C., Luna Sanchez, S., Mazo-Zea, R., Ortiz-Torres, B., Penagos-Corzo, J., \& Polanco, F. (2020). Cómo afrontar la pandemia del Coronavirus (Covid-19) en las Américas: recomendaciones y líneas de acción sobre salud mental.

Huarcaya-Victoria, J. (2020). Consideraciones sobre la salud mental en la pandemia de COVID-19. Revista Peruana de Medicina Experimental y Salud Pública, 37(2).

Ramírez-Ortiz, J., Castro-Quintero, D., Lerma-Córdoba, C., Yela-Ceballos, F., \& Escobar-Córdoba, F. (2020). CONSECUENCIAS DE LA PANDEMIA COVID 19 EN LA SALUD MENTAL ASOCIADAS AL AISLAMIENTO SOCIAL.

Ribot Reyes, V. D., Chang Paredes, N., \& González Castillo, A. (2020). Efectos de la COVID-19 en la salud mental de la población. Revista Habanera de Ciencias Médicas(19).

Ruiz, A. L., Arcaño, K., \& Pérez, D. (2020). La psicología como ciencia y profesión en el afrontamiento del COVID-19. Revista Caribeña de Psicología, 153-165.

Scholten, H., Quezada-Scholz, V., Salas, G., Barria-Asenjo, N., Rojas-Jara, C., Molina, R., \& Gó- 
mez-Muzzio, E. (2020). Abordaje psicológico del COVID-19: una revisión narrativa de la experiencia latinoamericana.

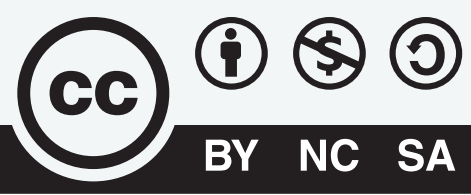

CREATIVE COMMONS RECONOCIMIENTO-NOCOMERCIAL-COMPARTIRIGUAL 4.0.

\section{CITAR ESTE ARTICULO:}

Ochoa Bustamante, J. P., Ortiz Dueñas, S. E., \& Rojas Riera, J. M. (2020). Lidiar con el estrés durante el brote de 2019-nCoV. RECIMUNDO, 4(4), 144-151. https://doi.org/10.26820/recimundo/4.(4).octubre.2020.144-151 